\title{
Multivariate Analysis on Extant Desi Cotton Genotypes (G. arboreum and G. herbaceum L.) Employing Qualitative Characteristics
}

\author{
K. Rathinavel*, C. Priyadharshini and H. Kavitha \\ Central Institute for Cotton Research, Regional Station, Coimbatore-641003, T.N., India \\ *Corresponding author
}

\author{
A B S T R A C T
}

\begin{tabular}{|l|}
\hline Ke y w o r d s \\
Morphological \\
character, DUS test, \\
Multivariate, \\
Clustering, Diversity, \\
Dendrogram. \\
\hline Article Info \\
\hline $\begin{array}{l}\text { Accepted: } \\
\text { 07 September } 2017 \\
\text { Available Online: } \\
\text { 10 November } 2017\end{array}$
\end{tabular}

\section{Introduction}

Cotton is the most important natural fiber crop known as 'white gold'. Cotton seeds are the major source of edible oil as well as cotton meal throughout the world (Pillay and Myers, 1999; Sunilkumar et al., 2006). The genus Gossypium contains 45 diploid and 6 allotetraploid species which spread across temperate and tropical regions of Africa, Australia, Central and South America, Arabia, Indian subcontinent, the Galapagos and Huawei (Fryxell, 1992). On the basis of chromosomal affinity studies, species of the genus Gossypium are grouped into eight (A-G and K) diploid genomes (Beasley, 1940; Endrizzi et al., 1985; Stewart, 1994). Members of each genome group have a morphological resemblance but they rarely form hybrids with species of other genome groups.

In cotton 4 species are under cultivation viz., Gossypium arboreum L. (A2A2) and Gossypium herbaceum L. (A1A1) are diploid $(2 \mathrm{n}=2 \mathrm{x}=26)$, while Gossypium hirsutum L. 
(AADD) and Gossypium barbadense L. (AADD) are tetraploid $(2 n=4 x=52)$. Both diploid cotton species, G. arboreum L. and $G$. herbaceum $\mathrm{L}$., $(\mathrm{n}=\mathrm{x}=13)$ are the cultivated "Old World" cotton species of genus Gossypium. The G. arboreum might be evolved from $G$. herbaceum because $G$. arboreum differs from $G$. herbaceum only at single reciprocal chromosomal translocation (Gerstel, 1953; Hutchinson, 1954). The Agenome cotton is a potentially important genetic resource for cotton breeding program (Sheidai 2008).

Characterisation and estimation of the magnitude of genotypic diversity of various traits of G. arboreum and G. herbaceum may lead to open up newer opportunities for initiating the breeding programs leading to development of new plant varieties. Characterization of cultivars is mandatory when they have opted for Plant Variety Protection. A new plant variety is considered for protection, If it is clearly distinguishable by at least one essential characteristics from any other variety whose existence is a matter of common knowledge in any country at the time of filing of the application, If subject to the variation that may be expected from the particular features of its propagation it is sufficiently uniform in its essential characteristics and If it's essential characteristics remain unchanged after repeated propagation or, in the case of a particular cycle of propagation, at the end of each such cycle. Hence, in the present study, a set of 57 extant diploid cotton genotypes were characterized and grouped.

\section{Materials and Methods}

The present study material consists of 57 diploid cotton genotypes which include both G. herbaceum and G. arboreum species. The trial was laid out in augmented design at Central Institute for Cotton Research,
Regional station, Coimbatore under maintenance of Diploid extant reference cotton varieties for the establishment of Distinctiveness Uniformity and Stability of a new cotton variety. The seeds were sown in $90 \mathrm{~cm}$ row to row distance and $30 \mathrm{~cm}$ between plants. Recommended agronomic and plant protection measures were adopted from sowing till harvest of the crop.

Morphological traits such as Hypocotyl pigmentation; Leaf colour, Pubescence, Nectaries, Petiole pigmentation, Shape; Stem hairiness, Time of flowering, Petal colour, Petal spot, Position of stigma, Anther filament colour; Boll colour, Shape (longitudinal section), texture of boll surface, Prominence of boll tip, boll opening, boll weight (g), Presence of seed fuzz, fuzz colour, Seed index (g), Ginning (\%) and fibre colour were recorded as per the procedure of Guidelines for the Conduct of Test for Distinctiveness, Uniformity and Stability on (Gossypium arboreum L. and G.herbaceum L.) of Protection of Plant Varieties and Farmers' Rights Authority (PPV and FRA)

Among the 26 traits studied, three were quantitative and they were converted into notes for analyses and rest was qualitative. These data were utilised for the assessment of range and extent of diversity exist among the extant diploid cotton varieties and grouping of varieties based on a specific trait. The statistical analysis of PCA and clustering were done using the software SPSS 16.0 and PAST 3 (Hammer et al., 2001).

\section{Results and Discussion}

\section{Characterisation of diploid cotton genotypes}

Polymorphism was found in all 23 traits observed (Table 1). The non-polymorphic traits observed were plant stem pigmentation, 
pollen colour and male sterility. The character hypocotyl pigmentation was absent in 10 genotypes (17.5) and rest of the genotypes (82.5) were pigmented. Green leaf colour (48) was predominant followed by light red (7), light green (1) and red (1) among genotypes.

Medium pubescence recorded in 42 genotypes followed by dense (8) and sparse (7). Leaf nectar glands present in 43 genotypes and in the rest it was absent. Petiole pigmentation was recorded in 48 genotypes out of 57 .

Among the genotypes, 40 genotypes had digitate leaf shape followed by palmate (16) and semi digitate (1). Dense stem hairiness was found in 37 genotypes followed by medium hairiness (19) and it was sparse in one genotype. The majority of the genotypes were habituated to late flowering and it was found one medium and one early.

Yellow colour petal predominantly appears (33) followed by pink (9), white (9), cream (4), red (1) and variegated (1). Petal spot noticed in all the genotypes except HD 266. The position of stigma was found exerted in 37 genotypes and in the rest, it was embedded (20). Anther filament coloured in 45 genotypes only. Green coloured boll found in 47 genotypes and red coloured bolls appeared in 10 genotypes. All genotypes bear ovate shaped boll except Ragavendra and V797. The boll surface was pitted in 52 and smooth in 5. Boll tip was found pointed in 30 genotypes and in the remaining, it was blunt (27).

Complete boll opening was recorded in 49 genotypes and remaining eight genotypes were semi open. Boll weight was medium in 46 genotypes followed by small (8) and large (3). Medium seed fuzz was found in 48 genotypes followed by dense (7) and naked (2). Fuzz colour was found grey in (54) followed by naked (2) and brown (1). Seed index, showed medium state in 33 genotypes followed by bold in 21, very bold in 2 and small in 1 genotype. Very high ginning \% recorded in 26 genotypes followed by high (14), medium (7), and low (5) and very low (5).

Among the traits recorded, petal colour was observed with higher variation (six States) followed by traits such as seed index and ginning \% with five states, however, remaining traits were with two to four states respectively. Most of these traits were essential for the establishment of Distinctiveness Uniformity and Stability of a new candidate variety as against the varieties in active commerce (reference varieties)

\section{Principal component analysis}

The present analysis revealed that, out of 23 principal components, nine principal components (PC) were with Eigen values $>1$ together accounted for $76.03 \%$ of the variability expressed in the diploid cotton genotypes (Table 2). The variations attributed to PC1 was 22.06 per cent due to the traits like petiole pigmentation, anther filament colouration, boll opening, boll surface, leaf shape, hypocotyl pigmentation, ginning percent, boll colour and leaf colour. PC2 holds for 10.55 per cent of the variability which was mainly contributed by petal colour, boll colour and leaf colour.

The variance obtained from PC3 $(8.60 \%)$ has mostly resulted from traits like seed fuzz, seed fuzz colour and stem hairiness. PC4 accounted for seed fuzz colour, fibre colour and boll shape with a variance of 6.77 per cent. The variance for PC5 was 6.75 per cent by anther filament colouration; PC6 (5.98 \%) for boll prominence of tip and fibre colour; PC7 (5.33) for the time of flowering and boll shape; PC8 (5.13\%) for petal spot and PC9 $(4.86 \%)$ for boll weight. 


\section{Spread out plot}

Spread out plot also named polygon as generated through the principal components analysis illustrated the genetic pattern of diploid cotton genotypes (Fig. 1). On the other hand, genotypes which clogged at the vertex of the polygon are farthest from point of origin, hence more diversified and are of high genetic value. The genotypes viz., G 27, CISAA-2/ (CICR 2), Lohit, HD 324, PAU
626, AKA 7, DS 5, HD 123, G.Cot.23 and G.Cot.17 were clogged at the vertex of the polygon. A similar result was reported by (Malik et al., 2013). These genotypes are very much useful for the breeding programme. Similarly, the herbaceum species are clogged at one side and rest of the genotypes are placed on the other side. The utilization of scatter plot to find out most phenomenal and divergent genotypes was done by Rehman et al., (2015) in cotton.

Table.1 Expression and Frequency distribution of morphological traits in Desi cotton genotypes

\begin{tabular}{|c|c|c|c|c|c|}
\hline Sl. No. & Descriptor & Scores & Category & $\begin{array}{l}\text { Number } \\
\text { of } \\
\text { genotypes }\end{array}$ & $\begin{array}{l}\text { Frequency } \\
(\%)\end{array}$ \\
\hline \multirow[t]{2}{*}{1} & \multirow[t]{2}{*}{ Hypocotyl: Pigmentation } & 1 & Absent & 10 & 17.5 \\
\hline & & 9 & Present & 47 & 82.5 \\
\hline \multirow[t]{4}{*}{2} & \multirow[t]{4}{*}{ Leaf: Colour } & 1 & Light green & 1 & 1.8 \\
\hline & & 2 & Green & 48 & 84.2 \\
\hline & & 3 & Light red & 7 & 12.3 \\
\hline & & 4 & Dark red & 1 & 1.8 \\
\hline \multirow[t]{3}{*}{3} & \multirow[t]{3}{*}{ Leaf: Pubescence } & 1 & Sparse & 7 & 12.3 \\
\hline & & 5 & Medium & 42 & 73.7 \\
\hline & & 9 & Dense & 8 & 14.0 \\
\hline \multirow[t]{2}{*}{4} & \multirow[t]{2}{*}{ Leaf: Nectaries } & 1 & Absent & 14 & 24.6 \\
\hline & & 9 & Present & 43 & 75.4 \\
\hline \multirow[t]{2}{*}{5} & \multirow{2}{*}{ Leaf: Petiole pigmentation } & 1 & Absent & 9 & 15.8 \\
\hline & & 9 & Present & 48 & 84.2 \\
\hline \multirow[t]{3}{*}{6} & \multirow[t]{3}{*}{ Leaf: Shape } & 1 & Palmate & 16 & 28.1 \\
\hline & & 2 & Semi-digitate & 1 & 1.8 \\
\hline & & 3 & Digitate & 40 & 70.2 \\
\hline \multirow[t]{4}{*}{7} & \multirow[t]{4}{*}{ Plant: Stem hairiness } & 1 & Absent & - & - \\
\hline & & 3 & Sparse & 1 & 1.8 \\
\hline & & 5 & Medium & 19 & 33.3 \\
\hline & & 7 & Dense & 37 & 64.9 \\
\hline \multirow[t]{2}{*}{8} & \multirow[t]{2}{*}{ Plant: Stem pigmentation } & 1 & Absent & - & - \\
\hline & & 9 & Present & 57 & 100 \\
\hline \multirow[t]{3}{*}{9} & \multirow[t]{3}{*}{ Flower: Time of flowering } & 3 & Early $(<50$ days $)$ & 1 & 1.8 \\
\hline & & 5 & Medium (50-60 days) & 1 & 1.8 \\
\hline & & 7 & Late $(>60$ days $)$ & 55 & 96.5 \\
\hline \multirow[t]{5}{*}{10} & \multirow[t]{5}{*}{ Flower: Petal colour } & 1 & White & 9 & 15.8 \\
\hline & & 2 & Cream & 4 & 7.0 \\
\hline & & 3 & Yellow & 33 & 57.9 \\
\hline & & 4 & Pink & 9 & 15.8 \\
\hline & & 5 & Red & 1 & 1.8 \\
\hline
\end{tabular}




\begin{tabular}{|c|c|c|c|c|c|}
\hline & & 6 & Variegated & 1 & 1.8 \\
\hline \multirow[t]{2}{*}{11} & \multirow[t]{2}{*}{ Flower: Petal spot } & 1 & Absent & 1 & 1.8 \\
\hline & & 9 & Present & 56 & 98.2 \\
\hline \multirow[t]{2}{*}{12} & \multirow[t]{2}{*}{ Flower: Stigma } & 3 & Embedded & 20 & 35.1 \\
\hline & & 5 & Exerted & 37 & 64.9 \\
\hline \multirow[t]{2}{*}{13} & \multirow[t]{2}{*}{ Flower: Anther Filament colour } & 1 & Absent & 12 & 21.1 \\
\hline & & 9 & Present & 45 & 78.9 \\
\hline \multirow[t]{2}{*}{14} & \multirow[t]{2}{*}{ Boll: Colour } & 3 & Green & 47 & 82.5 \\
\hline & & 5 & Red & 10 & 17.5 \\
\hline \multirow[t]{2}{*}{15} & \multirow[t]{2}{*}{ Flower: Pollen colour } & 1 & Cream & - & - \\
\hline & & 9 & Yellow & 57 & 100 \\
\hline \multirow[t]{2}{*}{16} & \multirow[t]{2}{*}{ Flower: Male Sterility } & 1 & Absent & 57 & 100 \\
\hline & & 9 & Present & - & - \\
\hline \multirow[t]{3}{*}{17} & \multirow[t]{3}{*}{ Boll: Shape } & 3 & Round & 2 & 3.5 \\
\hline & & 5 & Ovate & 55 & 96.5 \\
\hline & & 7 & Elliptic & - & - \\
\hline \multirow[t]{2}{*}{18} & \multirow[t]{2}{*}{ Boll: Surface } & 1 & Smooth & 5 & 8.8 \\
\hline & & 9 & Pitted & 52 & 91.2 \\
\hline \multirow[t]{2}{*}{19} & \multirow[t]{2}{*}{ Boll: Prominence of tip } & 1 & Blunt & 27 & 47.4 \\
\hline & & 9 & Pointed & 30 & 52.6 \\
\hline \multirow[t]{3}{*}{20} & \multirow{3}{*}{ Boll: Opening } & 3 & Semi-open & 8 & 14.0 \\
\hline & & 5 & Open & 49 & 86.0 \\
\hline & & 7 & Close & - & - \\
\hline \multirow[t]{3}{*}{21} & \multirow{3}{*}{$\begin{array}{l}\text { Boll weight of seed cotton/boll } \\
\text { (g) }\end{array}$} & 1 & Small $(<2.0)$ & 8 & 14.0 \\
\hline & & 3 & Medium (2.0-3.0) & 46 & 80.7 \\
\hline & & 5 & Large $(>3.0)$ & 3 & 5.3 \\
\hline \multirow[t]{3}{*}{22} & Seed: Fuzz & 1 & Naked & 2 & 3.5 \\
\hline & & 3 & Medium & 48 & 84.2 \\
\hline & & 5 & Dense & 7 & 12.3 \\
\hline 23 & Seed: Fuzz colour & 0 & Naked & 2 & 3.5 \\
\hline & & 1 & Grey & 54 & 94.7 \\
\hline & & 2 & Brown & 1 & 1.8 \\
\hline 24 & Seed index (100 seed wgt. in g) & 1 & Very small $(<3.0)$ & - & - \\
\hline & & 3 & Small (3.0-5.0) & 1 & 1.8 \\
\hline & & 5 & Medium (5.1-7.0) & 33 & 57.9 \\
\hline & & 7 & Bold (7.1-9.0) & 21 & 36.8 \\
\hline & & 9 & Very bold $(>9.0)$ & 2 & 3.5 \\
\hline 25 & Ginning (\%) & 1 & Very low $(\leq 30)$ & 5 & 8.8 \\
\hline & & 3 & Low (31-32) & 5 & 8.8 \\
\hline & & 5 & Medium (33-34) & 7 & 12.3 \\
\hline & & 7 & High (35-36) & 14 & 24.6 \\
\hline & & 9 & Very high $(\geq 37)$ & 26 & 45.6 \\
\hline 26 & Fibre: Colour & 1 & White & 37 & 64.9 \\
\hline & & 2 & Cream & 19 & 33.3 \\
\hline & & 3 & Green & - & - \\
\hline & & 4 & Brown & 1 & 1.8 \\
\hline
\end{tabular}


Table.2 Analysis of principal components with Eigen values $>1$

\begin{tabular}{|c|c|c|c|c|c|c|c|c|c|}
\hline \multirow[t]{2}{*}{ Traits } & \multicolumn{9}{|c|}{ Components } \\
\hline & PCA 1 & PCA 2 & PCA 3 & PCA 4 & PCA 5 & PCA 6 & PCA 7 & PCA 8 & PCA 9 \\
\hline Hypocotyl pigmentation & 0.558 & 0.023 & -0.321 & 0.335 & 0.203 & -0.184 & 0.145 & 0.149 & -0.249 \\
\hline Leaf colour & 0.432 & 0.787 & 0.124 & -0.111 & -0.001 & 0.056 & -0.007 & 0.055 & -0.157 \\
\hline Leaf hairiness & -0.634 & 0.095 & -0.133 & 0.204 & 0.291 & -0.164 & 0.219 & -0.321 & 0.125 \\
\hline Leaf nectaries & -0.391 & 0.079 & -0.229 & 0.333 & 0.347 & -0.218 & -0.076 & -0.237 & -0.532 \\
\hline Petiole pigmentation & 0.831 & -0.162 & 0.173 & -0.16 & 0.294 & -0.096 & -0.106 & -0.163 & -0.102 \\
\hline Leaf shape & 0.643 & -0.315 & -0.012 & -0.033 & -0.148 & 0.29 & -0.069 & 0.052 & 0.074 \\
\hline Stem hairiness & -0.169 & 0.249 & 0.452 & 0.234 & 0.174 & -0.19 & -0.017 & 0.305 & 0.078 \\
\hline Time of flowering & -0.106 & 0.049 & 0.213 & -0.34 & -0.152 & -0.227 & 0.655 & 0.216 & -0.205 \\
\hline Petal colour & 0 & 0.807 & -0.048 & 0.127 & 0.322 & -0.101 & -0.191 & 0.055 & 0.207 \\
\hline Petal spot & -0.116 & -0.34 & 0.175 & 0.062 & 0.366 & -0.129 & -0.073 & 0.602 & 0.319 \\
\hline Stigma & -0.399 & -0.054 & 0.345 & -0.203 & 0.304 & 0.035 & 0.304 & 0.129 & -0.21 \\
\hline Anther filament colouration & 0.759 & -0.24 & 0.159 & 0.018 & 0.459 & -0.085 & 0.019 & 0.105 & 0.026 \\
\hline Boll colour & 0.444 & 0.807 & 0.098 & -0.083 & -0.118 & -0.052 & 0.026 & 0.101 & 0.091 \\
\hline Boll shape & 0.242 & 0.029 & -0.397 & 0.448 & -0.149 & 0.112 & 0.501 & 0.247 & 0.097 \\
\hline Boll surface & 0.687 & -0.103 & 0.007 & 0.161 & 0.234 & 0.325 & 0.245 & -0.057 & 0 \\
\hline Boll prominence of tip & 0.318 & 0.27 & -0.225 & -0.048 & 0.127 & 0.635 & 0.109 & -0.069 & 0.087 \\
\hline Boll opening & 0.698 & -0.122 & 0.174 & -0.189 & 0.332 & -0.146 & -0.08 & -0.209 & -0.081 \\
\hline Boll weight & 0.271 & -0.087 & -0.213 & 0.367 & 0.033 & -0.327 & 0.183 & -0.268 & 0.48 \\
\hline Seed fuzz & -0.189 & -0.01 & 0.714 & 0.109 & 0.067 & 0.192 & 0.197 & -0.382 & 0.24 \\
\hline Seed fuzz colour & -0.046 & 0.04 & 0.675 & 0.546 & -0.183 & 0.152 & 0.025 & -0.108 & -0.072 \\
\hline Seed index & -0.626 & 0.025 & -0.179 & -0.198 & 0.325 & 0.181 & -0.165 & 0.081 & 0.269 \\
\hline Ginning \% & 0.455 & -0.083 & 0.188 & 0.268 & -0.475 & -0.318 & -0.303 & 0.101 & -0.016 \\
\hline Fiber colour & -0.325 & -0.078 & 0.077 & 0.441 & 0.127 & 0.45 & -0.221 & 0.251 & -0.284 \\
\hline Eigen value & 5.07 & 2.43 & 1.98 & 1.56 & 1.55 & 1.38 & 1.23 & 1.18 & 1.12 \\
\hline Variability (\%) & 22.06 & 10.55 & 8.6 & 6.77 & 6.75 & 5.98 & 5.33 & 5.13 & 4.86 \\
\hline Cumulative variability (\%) & 22.06 & 32.61 & 41.21 & 47.98 & 54.73 & 60.71 & 66.04 & 71.17 & 76.03 \\
\hline
\end{tabular}


Table.3 Clustering pattern of Desi cotton genotypes

\begin{tabular}{|c|c|c|c|}
\hline Clusters & Groups & No. of genotypes & Genotypes \\
\hline \multirow[t]{2}{*}{ I } & 1 & 5 & Jawahar Tapti, Sujay, Digvijay, G. Cot. 13, Jayadhar \\
\hline & 2 & 5 & 4011, G. Cot. 23, G.Cot. 17, V797, G.Cot.21 \\
\hline \multirow[t]{4}{*}{ II } & 1 & 5 & Dhumad, DS 5, HD 123, GMS line, GMS 1 \\
\hline & 2 & 2 & Ragavendra, G.Cot. DH7 \\
\hline & 3 & 3 & RG 8, AKA 7, RG 18, \\
\hline & 4 & 10 & HD 107, Aravinda, DLSa 17, Veena, K10, K11, Y1, AKH 4, AKA 5, AKA 8401 \\
\hline III & 1 & 7 & GAK 423, Moti, PAU 626, LD 694, CISAA 2/(CICR2), HD 324, G.Cot.15 \\
\hline \multirow[t]{3}{*}{ IV } & 1 & 5 & G.Cot. DH 9, Cat No. 8397, 824, LD 327, PKV DH1 \\
\hline & 2 & 2 & AAH1, HD 266 \\
\hline & 3 & 13 & Lohit, G 27, PA 183, Cat No.8999, Cat No.8405, JLA 794, AKA 590, K9, PA 255, HD110-151, LD 491, G.Cot.19, LD 210 \\
\hline
\end{tabular}

Fig.1 Spread out plot of diploid cotton genotypes

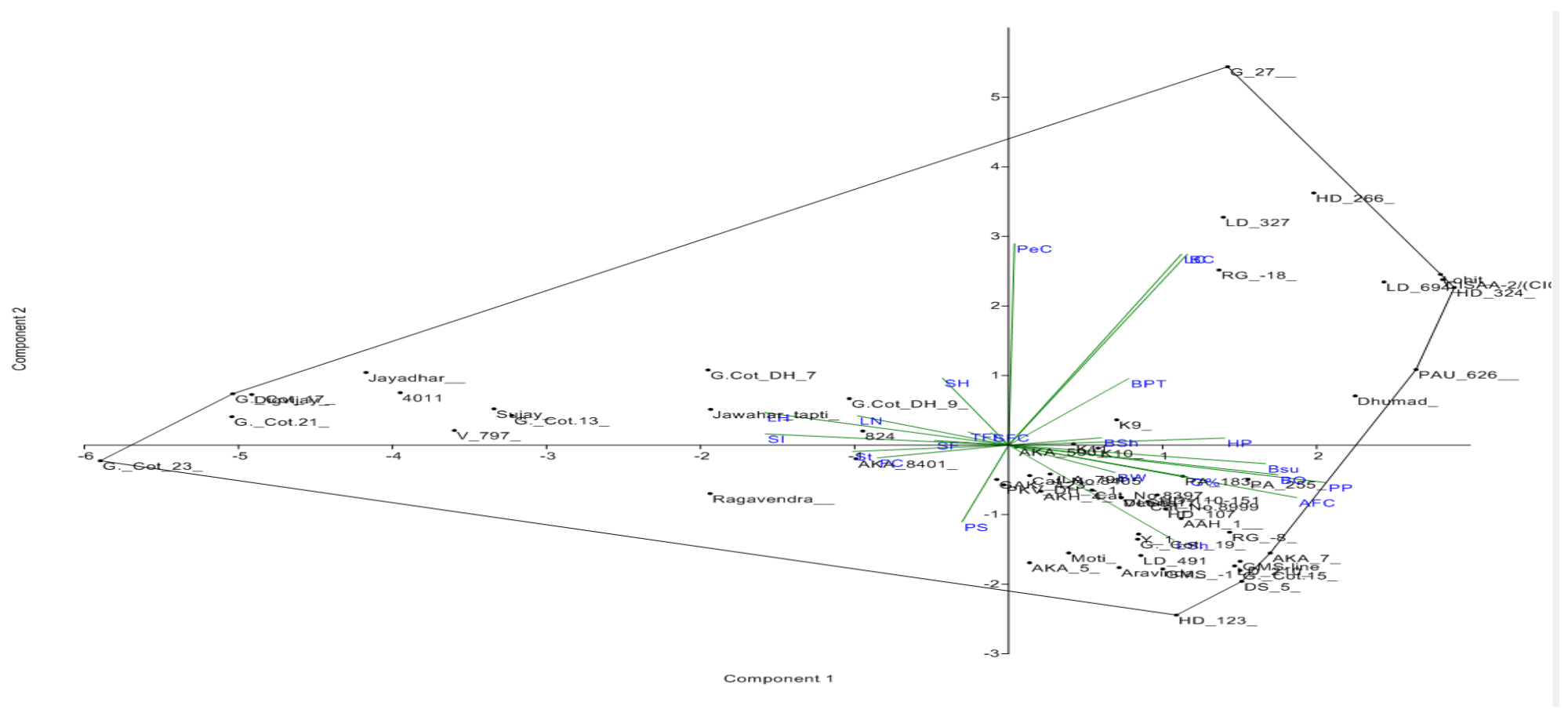


Fig.2 Screen plot showing the Eigen values of different principal component of diploid cotton genotypes

\section{Scree Plot}

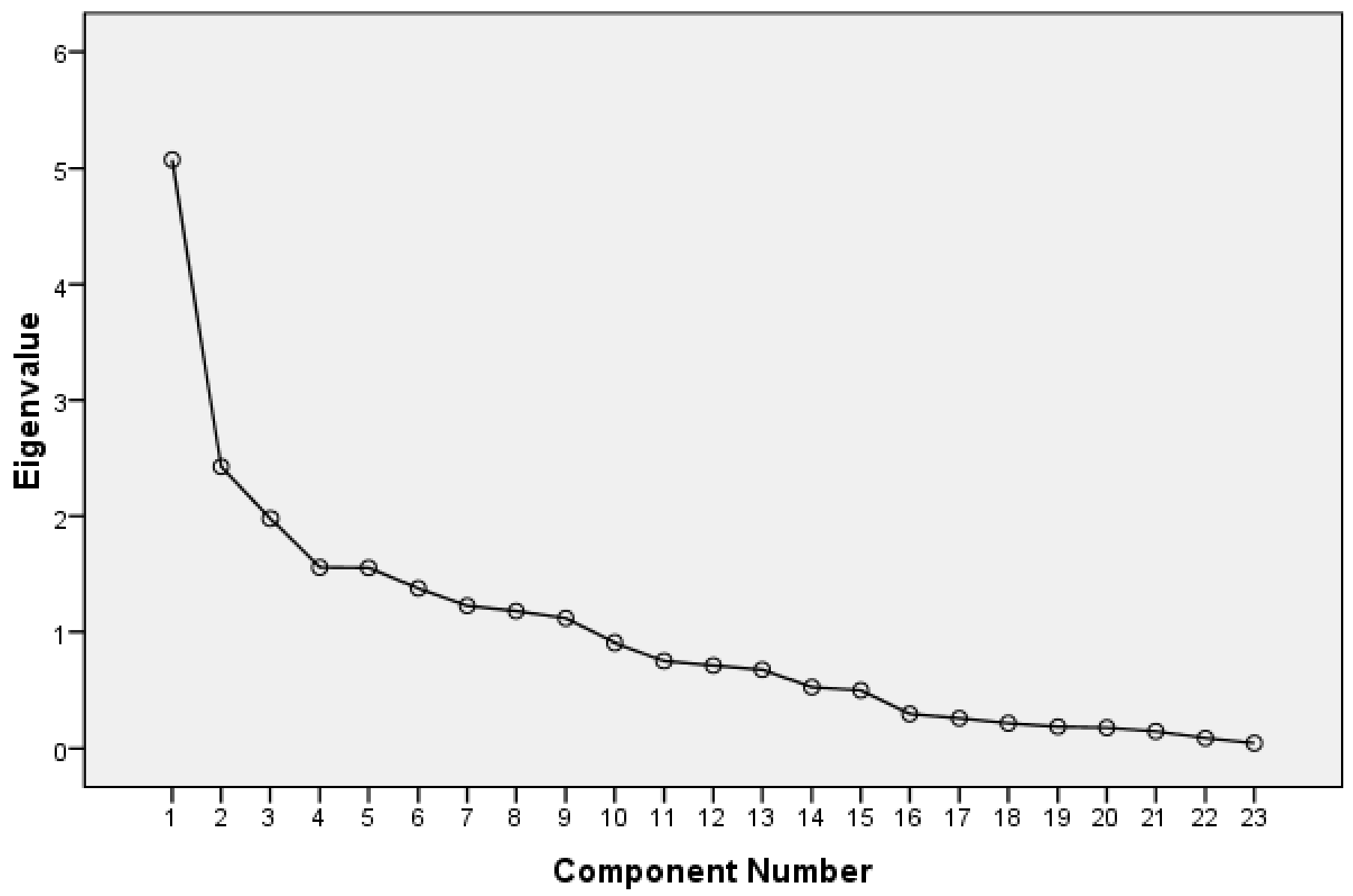


Fig.3 Dendrogram showing the clusters drawn using Ward's minimum variance

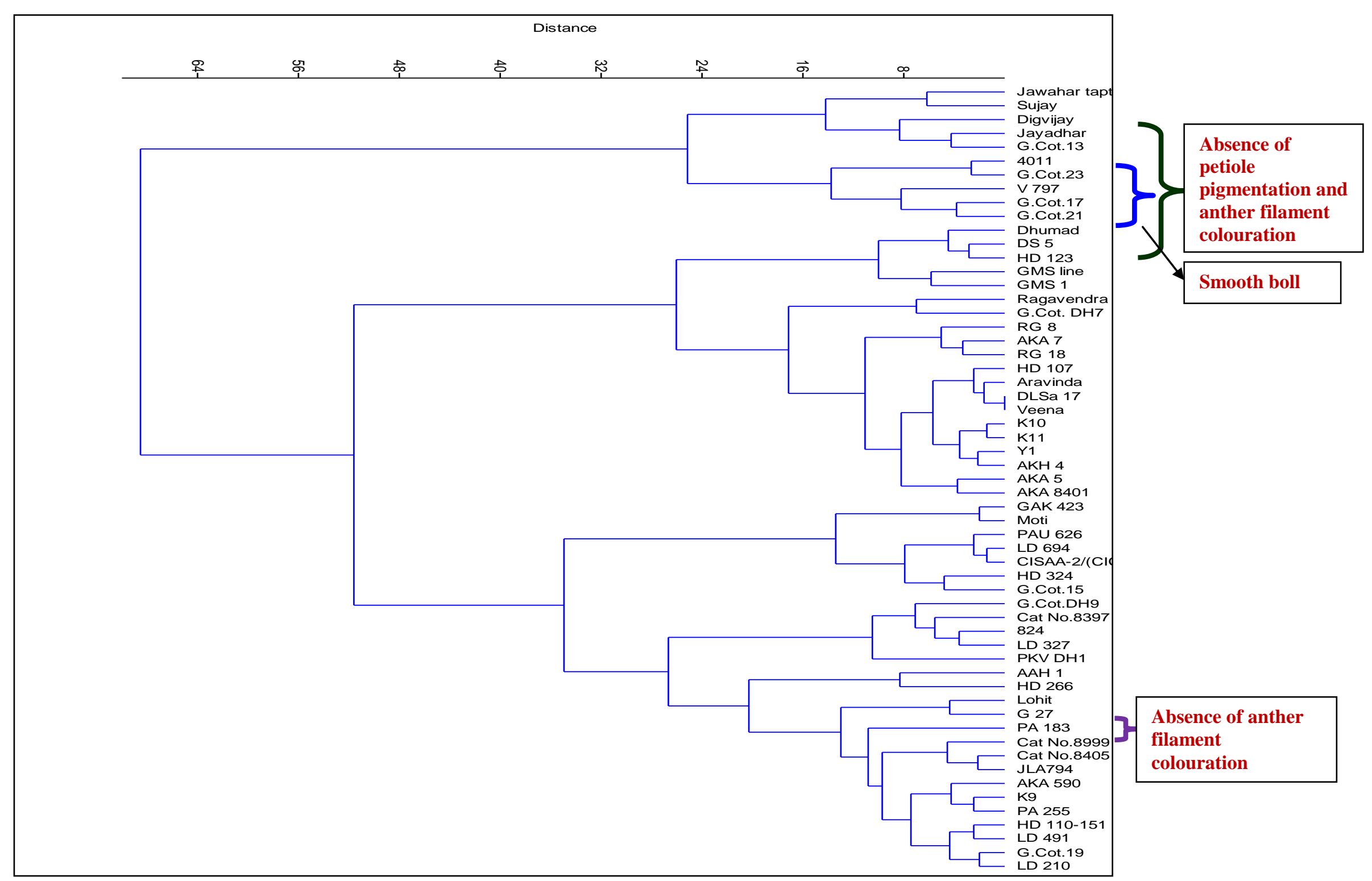




\section{Screen plot}

Screen plot exhibited variance percentage associated with each principal component attained by drawing a graph between Eigen value and PC numbers. PC1 showed 22.06\% variability followed by PC2 with $10.55 \%$ having Eigen values of 5.08 and 2.43 respectively in Figure 2.

\section{Cluster analysis}

The genotypes characterised in the present study were grouped into four clusters by using Ward's minimum distance variance method. The diploid genotypes consist of both $G$. arboreum and $G$. herbaceum species. The herbaceum under genotypes were grouped in cluster I, however, the genotype Jawahar tapti which belongs to G. arboreum also grouped in this cluster. The cluster I consist of totally 10 genotypes with two groups 1 and 2 each containing 5 genotypes. The cluster II consisted of 20 genotypes which form four groups each containing 5, 2, 3 and 10 genotypes, respectively. The cluster III encompasses seven genotypes and cluster IV with 20 genotypes, which form three groups in each containing 5,2 and 13 genotypes, respectively. Among these clusters, cluster IV was found the largest containing 20 genotypes followed by cluster II, I and III (Table 3 ). The genotypes all in cluster I had expressed no anther filament colour, petiole pigmentation and the bolls were of smooth surface, likewise, the cluster IV had absence of anther filament colouration in group 2 (AAH1 and HD 266) (Fig. 3). Therefore, the genotypes thus grouped may be a potential source of the morphological marker with specific trait and can be used as a reference variety for future crop improvement programme.

In this study, the characteristic stem pigmentation, pollen colour and male sterility were shown non polymorphic expression and hence 23 traits were included for the principal component analysis and clustering. Multivariate analysis is a valid system to evaluate germplasm in cotton, which has a key function of characterization of the genotypes (Iqbal et al., 2015). The PC analysis summarized the total variation into 23 PCs, out of which nine PCs contributed $76.03 \%$ of variation to the overall diversity among the diploid cotton genotypes studied. The genotypes like G 27, CISAA-2/ (CICR 2), Lohit, HD 324, PAU 626, AKA 7, DS5, HD 123, G.Cot.23 and G.Cot.17 were found at the vertex of the polygon and are more diversified. The cluster analysis formed four clusters and the genotypes of $G$. herbaceum species were clustered together to form a different cluster. This result is in concurrence with the spread out plot method.

\section{Acknowledgement}

The authors profusely thank and sincerely acknowledge the Protection of Plant Varieties and Farmers Rights Authority, New Delhi for its generous financial support.

\section{References}

Beasley, J., 1940. The production of polyploids in Gossypium. J. Hered., 31: 39-48.

Endrizzi, J., E. Turcotte and Kohel, R.1985. Genetics, Cytology, and Evolution of Gossypium. Adv Genet., 23: 271-375.

Fryxell, P., 1992. A revised taxonomic interpretation of Gossypium L.(Malvaceae). Rheedea, 2(2): 108-165.

Gerstel,D., 1953. Chromosomal translocations in interspecific hybrids of the genus Gossypium. Evolution, 234-244.

Hammer, O., D.A.T, Harper and Ryan, P.D. 2001. PAST: Paleontological statistics software package for education and data analysis. Palaeontol. Electr. 4: 1-9

Hutchinson, J.B. 1954. New evidence on the 
origin of the old world cottons. Heredity, 8(2): 225-241.

Iqbal, M.A., A.Abbas, Y. Zafar and Rahman, M. 2015. Characterization of indigenous gossypium arboreum genotypes for various fiber quality traits. Pakistan Journal of Botany, 47(6): 2347-2354.

Malik, W., A.A.Khan and Sadia, B. 2013. "In situ characterization of coloured cotton genotypes." Australian J. Crop Sci, 7(3): 299-304.

Pillay, M. and Myers, G. 1999. Genetic diversity in cotton assessed by variation in ribosomal RNA genes and AFLP markers. Crop Sci., 39(6): 1881-1886.

Rehman, S.U., M.A. Abid, W. Malik, C.M. Hanif, M. Bilal and Qanmber, G. 2015. "Exploitation of Germplasm for Plant Yield Improvement in Cotton (Gossypium hirsutum L.)." J. Green
Physiol. Gen. Genom., 1(1).

Sheidai,M., 2008. Cytogenetic distinctiveness of sixty-six tetraploid cotton (Gossypium hirsutum L.) cultivars based on meiotic data. Acta Botanica Croatica, 67: 209-20.

Stewart, J.M., 1994. Potential for crop improvement with exotic germplasm and genetic engineering. In: (Eds.): G.A. Constable and N.W. Forrester, Challenging the future, Proceedings World Cotton Res. Conf. -1 , Brisbane (AUS), pp. 313-327.

Sunilkumar, G., L.M. Campbell, L. Puckhaber, R.D. Stipanovic and Rathore, K.S. 2006. Engineering cottonseed for use in human nutrition by tissue-specific reduction of toxic gossypol. Proc. Natl. Acad. Sci., 103(48): 18054 - 18059.

\section{How to cite this article:}

Rathinavel, K., C. Priyadharshini and Kavitha, H. 2017. Multivariate Analysis on Extant Desi Cotton Genotypes ( $G$. arboreum and G. herbaceum L.) Employing Qualitative Characteristics. Int.J.Curr.Microbiol.App.Sci. 6(11): 724-734. doi: https://doi.org/10.20546/ijcmas.2017.611.085 